\title{
Modern Interpretation of Traditional "Benevolence" Culture in Ideological and Political Education
}

\author{
Zhang $\mathrm{Li}^{1,}$ a, $\mathrm{Wu} \mathrm{Lang}^{2, \mathrm{~b}^{*}}$ \\ ${ }^{1}$ Architectural Engineering Institute, Jiangxi Science and Technology Normal University, Nan Chang, China \\ ${ }^{2}$ Architectural Engineering Institute, Jiangxi Science and Technology Normal University, Nan Chang, China \\ a30693365@qq.com \\ b*348385613@qq.com
}

\begin{abstract}
The traditional "benevolence" culture is the essence of Chinese culture and the theoretical basis for the formation of Chinese national values. This paper analyzes the basic connotation of Chinese traditional "benevolence" culture, probes into the modern value of traditional "benevolence" culture in Ideological and political education, systematically expounds the way of Ideological and political education of the integration of traditional "benevolence" culture in an all-round way, and seeks the power and resources for the reconstruction of the values construction of the new generation of young college students and the revival of traditional culture.
\end{abstract}

Keywords: the traditional "benevolence" culture, Ideological and political education, modern interpretation

\section{传统 “仁”文化在思想政治教育工作中的现代诠释 \\ 张丽 $1, a$ 吴浪 $2, b^{*}$}

1 江西科技师范大学建筑工程学院, 南昌, 江西

2 江西科技师范大学建筑工程学院, 南昌, 江西

a30693365@qq.com

b*348385613@qq.com

\section{摘要}

传统 “仁” 文化是中国文化的精髓，是我国民族价值观念形成的理论基础。对中国传统 “仁” 文化的 基本内涵等展开分析，探讨传统 “仁” 文化在思想政治教育工作中的现代价值，全方位系统阐述传统 “仁” 文化融合思想政治教育工作途径，为重塑新一代青年大学生的价值观建设、传统文化的复兴寻 找动力与资源。

关键词：传统 “仁”文化；思想政治教育；现代诠释

\section{1. 前言}

源远流长的儒家传统 “仁”文化在中国人长期性格 形成、修养境界和文化素质提升方面, 有着无可替代的 地位和传承作用。作为儒家传统文化核心的 “仁” 文化, 以“孝悌”为起点, “亲亲”, “泛爱众”, 再推己及人, “穷则独善其身，达则兼济天下” [1]，对中国人思维方 式和行为习惯产生深远的影响, 而且更为重要的是传统 “仁” 文化到了今时今日仍旧为我们的道德教育提供一 种有益的思维视角和价值取向。

习近平总书记曾经在多个场合数次强调重视传统
文化和儒家思想对于中华民族伟大复兴的深刻意义，认 为这是中国人所特有的精神世界、它塑造了百姓日用而 不觉的价值观。习近平总书记将青年时期的价值观比喻 为 “人生的第一粒扣子”, 如何将传统 “仁” 文化价值 部分嫁接入大学生的价值教育中, 从而对其未来发展起 到重要影响作用是个非常值得研究的问题。与此同时, 在新的历史条件下，“仁”文化是否还能够在在塑造当 代大学生的信仰和品格中起到一定的引导和传承作用? 对这一系列问题的研究和理解, 显得尤为重要。

为此, 笔者在南昌 3 所本科高校进行了相关的调研, 调研方式以深度访谈为主, 主要面向对象是 1985-1992 年之间出生的高校思想政治教育工作者。论文将从这一 访谈获得的资料入手，对中国传统 “仁” 文化的基本内 
爱” 道德意识渗透到学生的内心深处, 教导学生要 “爱” 他人, “爱” 集体, “爱” 生活, “爱” 社会, 树立正确 的 “爱” 世界观、人生观以及价值观。

\section{2 “兼济天下” 的家国情怀}

中国传统 “仁” 文化重视 “兼济天下”的家国情怀 的培养和理想的塑造。历代的儒家学者把 “人格” 等问 题进行深层次的提炼, 提出了种种人生标准和理想目 标, 这就是所谓的 “家国情怀”。儒家 “家国情怀” 是 志士仁人, 它要求士人 “德才兼备”、“德惠双修”，提 倡 “达则兼济天下，穷则独善其身”。要求每个人不管 身处如何境地, 都不可降自己的志气, 丧失节操, 而要 持身立节, 正道直行。“穷则独善其身, 达则兼济天下” 中传达出来传统 “仁” 文化的为国、为民、为天下的家 国情怀, 更体现出由己及人的无私奉献精神。《礼记》 中 “大道之行也, 天下为公”, 也就是受 “仁爱” 思想 的驱动, 将天下利益为先。范仲淹 “先天下之忧而忧, 后天下之乐而乐” 的 “仁爱” 观念，把传统 “仁” 文化 中的家国情怀推到极致。这种家国天下的责任感到了清 代，就又延伸出 “国家兴亡，匹夫有责”，把 “仁” 的 思想演绎到行动中来, 并对天下人提出 “有责” 的要求。 “仁爱” 从 “老吾老以及人之老, 幼吾幼以及人之幼” 到 “兼济天下” 的崇高家国精神以及对整个人类所具有 的责任感与使命感, 有助于弘扬爱国主义精神以及集体 主义精神, 有利于克服利已主义, 对抗腐败堕落行为。

\section{3 “师以身为正仪” 的修身情怀}

\section{1 “仁者爱人” 的人文情怀}

“仁者, 莫大于爱”, 传统 “仁” 文化的核心是一 个 “爱” 字, “仁者爱人” 倡导的就是拥有仁心的人要 懂得去爱护别人，从而达到 “兼爱” 的目的。孔子相信 “为仁由已”, 即一切 “仁” 的修养全在于人的自身的 修养。一个人如果想实现 “仁”, 只有经过自我内心的 不断淬炼和行为的自我约束, 不能依靠外在的环境与压 力。 “为仁由已” 思想的深层含义指人要从自我的道德 修养出发, 具备自我内在的价值及对这种价值的认可与 自觉, 蕴含着自我完善与发展。由此可以看出, 传统“仁” 文化主张通过自己的主观努力来实现人的道德本性, 在 方法上讲求 “自治”、“慎独”, 要求每一个人在道德与 行为上认真反省自己, 时刻检查自己的过失, 调整自己 的行为, 使自己的思想和行为不断合乎社会的道德伦理 规范, “穷则独善其身” 就很好的诠释了传统 “仁” 文 化在自我的道德修养中有严格的要求。就 “仁” 文化本 身而言, 其对构建良好和谐的人际关系, 有着至关重要 的思想引导作用。做好学生的思想政治工作, 就要充分 发挥 “仁” 文化的精华部分, 把传统 “仁爱” 思想应 用于思想政治工作中, 让学生能够拥有 “仁爱”之心, 能够在 “仁” 的引导下热爱身边的人和物, 使这种 “大
从孔子提出的 “其身正，不令而从; 其身不正，虽 令不从。” 到荀子的 “仁言不如仁声之入人深也。”, 都 在说明用 “仁厚” 的言语教人行仁德, 不如用表达仁的 行动教人行仁德的功效大。荀子曾提出 “师以身为正 仪”, 把身为师长的身教示范作用鲜明地凸显了出来。 此外, 孔子要求 “言而有信”, 强调 “敏于事而甚于言”

(《论语- 学而》)。作为传统 “仁” 文化的延伸, 对教 师的品德修养提出很高的要求。但是笔者认为, 这是 “仁” 文化对自我修养做出的道德约束，和 “温故而知 新”、“学而不思则罔, 思而不学则殆”、“教亦多术”, “银 而不舍”, “业精于勤荒于嬉” 等, 对于教师自身个人修 养道德层面的要求, 这个要求可以影响教师的教学观及 学生的自我修养观, 此思想内涵对深化师范类院校学生 的思想道德修养具有潜在的教育启发意义。

\section{3. 传统 “仁”文化在思想政治教育工作中的现 代价值}

中国传统 “仁”文化在儒家思想为主导的历史时期, 对当时的社会价值和主流思想取向形成占据着主流作 用。在当今中西文化思想意识激励碰撞的新时代背景 
下，将中国传统 “仁” 文化中的积极因子融入到思想政 治教育工作中显得尤为重要。高校要引导大学生自觉主 动地吸收传统 “仁” 文化中积极健康向上的部分, 引导 大学生树立正确的世界观、人生观、价值观, 在行动上 踏实践行社会主义核心价值观, 落实到具体工作中, 可 从以下几个方面发挥中国传统 “仁”文化的价值。

\section{1 为思想政治教育工作提供教育目标}

《大学》开篇讲到: “大学之道, 在明明德, 在亲民, 在止于至善” ${ }^{[2]}$ 。大学教育的目的培养具有健全人格及 具有道德感的公民。中国传统 “仁” 文化重视人性本身 的引导和塑造, 与新时代背景下提出的社会主义核心价 值观有共同的契合点。“君子忧道忧贫” 中的爱国意识 和社会主义核心价值观中的 “爱国” 有相同的价值取向, “慎独” “自省” 就是要求人在自己一个人的时候也不 要做坏事, 要做好自我行为和精神上的独立自主, 和社 会主义核心价值观中个人层面的 “诚信” “友善” 在个 人思想修养方面具有异曲同工之处。中国传统 “仁” 文 化已经为思想政治工作提了教育目标, 那就是符合社会 主义核心价值观的合格人才。

这就要求高校进行思想政治教育工作一方面要理 解传统 “仁” 文化中的自省观, 要充分进行自我意识修 正及反省, 及时有效调节自身的行为。另一方面, 思想 政治教育工作者要站在 “家国” 的高度, 自觉树立开阔 的理想和心胸, 追求更高的思想境界, 树立正确的世界 观、价值观、人生观, 在实现自我完善的情况下能够对 学生在人格及道德上以良好的影响。

\section{2 为高校思想政治教育工作提供道德教育 价值}

德育是高校进行对大学生进行思想政治教育和素 质教育的灵魂, 高校在思想政治教育过程中要始终把 “育人” 作为教育发展的根本, 把学生 “德育” 放在成 长成才的重中之重。目前社会和高校教育的功利化冲淡 了 “德育” 在学生成长成才中的作用。传统 “仁” 文化 主张用道德原则来校正混乱的社会秩序和颠倒的人伦 关系, 建立以 “仁” 为最高标准, 以 “孝悌” 为最基本 规范的伦理关系。这些道德规范以及注重以德为先, 突 出以德教为方式的教育原则, 对思想政治教育重视以德 育方式教育人、引导人、培养人, 注重提高人的德性品 行等方面的教育主张, 具有较好的启示意义 ${ }^{[3]}$ 。

随着经济急速发展和手机网络的普及, 大学生的生 活及思想行为发生重大改变, 随之而来的是德育内容及 德育方式的变化。关于道德教育, 在传统 “仁” 文化中 也提出很多要求。如 “取法于上, 仅得为中; 取法于中, 故为其下”, 这是唐太宗李世民自撰的一部论述为君之 道的政治文献, 是对传统 “仁” 文化中道德标准的最好 诠释。在大学生道德教育中, 我们可以理解和诠释为道 德的建立必须树立一个 “上” 的标杆及榜样。道德标杆
及榜样树立之后，传统 “仁” 文化又对道德的重要性做 了一个更好的层次递增式的价值标准, “一心可以丧邦, 一心可以兴邦，只在公私之间尔”，这是是北宋思想家 程影、程臨兄弟对《论语子路》中孔子对道德的阐述, “公私”之间，可以 “丧邦”，也可 “兴邦”。 ${ }^{[4]}$ 而传统 “仁” 文化的对道德的树立和延伸, 终究是为了 “兼济 天下”。因此必须树立道德标杆榜样, 明白道德的重要 性, 尤其对思想政治教育工作者来讲, 保持自身高尚的 道德感更重要。

\section{3 为高校思想政治教育工作提供现代转型 路径}

我国传统 “仁” 文化强调 “道德”、“仁义” 等, 这 些理论为高校思想政治教育提供了理论资源, 更为思想 政治教育工作提供了一个传统文化转型的现代路径。传 统 “仁” 文化包含了道德、劝学、家国、立身等思想。 以《习近平用典》为例, 习近平总书记运用了传统文化 中的典故, 对更好认识历史发展规律, 更加坚定道路自 信、理论自信、制度自信, 肩负起坚持和发展中国特色 社会主义的历史责任具有重要的作用。思想政治教育工 作者可以借鉴习近平总书记引经用典的方式, 对现代社 会的问题进行诠释，结合传统 “仁” 文化与历史和新时 代的碰撞中发展的社会主义核心价值观，进一步挖掘传 统文化中蕴含的宝贵财富, 努力培养德才兼备的社会主 义建设者和接班人。

\section{4. 思想政治教育工作者对传统 “仁” 文化的现 代意义认识}

\section{1 青年思想政治教育工作者对传统 “仁”文 化与社会现实相结合的认识}

传统“仁”文化的继承和弘扬要与社会现实相结合, 是新时代青年一代对儒家经典 “仁” 文化在现代社会中 的意义的基本认识。习近平总书记在纪念孔子诞辰 2565 周年国际学术研讨会上发表讲话, 列举了中国优 秀传统文化中 15 项对治国理政有有益启发和启示的内 容。这些内容在青年大学生和青年教师中引起了广泛而 热烈的议论。在年轻思想政治教育工作者（1985-1992 年) 看来，传统价值意义的判断有两条：新时代是否需 要、个体是否可以做到。“仁者爱人、以德立人” 在青 年思想政治教育工作者中得到的认同度最高, 这是传统 与现实碰撞后在当代青年教育者中形成的共振。青年思 想政治教育工作者职业流动性强, 年轻人急功近利和功 利主义者不乏其人, 焦虑和浮躁的社会心态投射在青年 思想政治教育工作者的身上，因而，他们期待能够回归 传统, 坚守作为教育者的 “仁” 爱之心, 也渴望能够在 教育学生的时候能够以德服人, 给学生以好的引导和鼓 励。青年思想政治教育工作者都基本拥有作为教师最基 
导向，要注重目的性、时效性和创新性，需要进一步改 变传统教学内容及教学方式。

边的人，能够兼爱，能够 “立德” 成为青年思想政治教 育工作者最希望得到弘扬的精神品质。新一代青年思想 政治教育工作者也是非常强调自我意识和个体感受, 对 于自上而下的灌输表现出冷漠疏离的态度, 对传统价值 观念的建设更强调自身感受和体会。所以, 青年思想政 治教育工作者看待传统 “仁” 文化的现代意义时, 更注 重的是与现实结合、与自身阅历和感受相结合的那些内 容。

\section{2 青年思想政治教育工作者对传统 “仁”文 化与社会思想建设的认识}

传统 “仁” 文化中 “仁者爱人” 观念对当代社会思 想建设具有最为直接的意义。当前社会青年个体观念和 意念非常突出, 对于照顾他人感受成为奢侈品, 尤其是 青年一代都喜欢沉迷电子产品, 社会交往意愿下降, 只 想管好自己的一亩三分地，极少去关心爱护身边的人。 传统 “仁” 文化 “仁者爱人” 对当前大学生的思想建设 可以做出贡献, 可以强化学生 “爱人”。在这个问题上, 青年思想政治教育工作者的态度和理解可以分为两个 层次:

第一层, “仁”与 “爱” 是合二为一的。访谈中, 一位青年思想政治教育工作者谈到: “一味求 “仁” 是 错, 必先有自己的底线; 一味求 “爱” 是错, 必先爱自 己。在青年思想政治教育工作者的观念中, 要想爱人, 必须先要爱自己, 对别人 “仁”, 先要照顾好自己。青 年思想政治教育工作者在认识 “仁” 的观念时, 仍然 会从个人理念和个人情感出发, 先自爱, 再爱人, 再育 人, “仁爱” 是不能够分开的。

第二层, “仁” 文化的含义需要根据新的形势和新 的需要重新缔造。时代变了、教育对象变了, “仁” 文 化要随着进行新的补充和定义。在青年思想政治教育工 作者的观念中, 传统社会中的 “仁” 文化是规范社会道 德和个人行为的约束力, 但是大学生已经有了新的特 征, 社会也有了新的社会结构, 教育也有了新的内容。 所以，应该给 “仁” 文化赋予新的内容。爱护自己、爱 父母、爱家人, 之后才是爱学生、爱学校、爱社会。但 是在采访中, 青年思想政治教育工作者对于这个说法做 了相应的补充, 大家一致认为, 在所有 “仁” 爱的前提 下, 是爱祖国, 这是我们每一个中国人都必须做的事情, 在我们祖国有需要的时候, 青年一代, 不论在何时何地 都会挺身而出, 为了祖国而战。这说明 “仁” 观念是进 步的, 是伴随着时代特征的爱国因素发展流变的, 在热 爱祖国、热爱中国共产党的前提下的 “仁爱” 的理念, 这样才是将传统 “仁” 文化的价值观念作为一个整体来 继承和发扬, 而不是片面的、割裂的。

\section{5. 传统 “仁” 文化融合思想政治教育工作途径}

要实现传统 “仁” 文化对思想政治教育工作的价值

\section{1 传统 “仁” 文化思想政治内容进思政课堂}

从目前高校思想政治教育的情况来看, 有内在因素 和外在因素。内在因素也就是自身因素, 主要指学生自 己的条件和自身学习的意愿; 外在因素比较广泛这里指 的是学校因素, 包括学校对思想政治教育工作者参与思 想政治教育有什么政策, 对学生进行思想政治教育是在 课内还是课外。有相当一部分高校没有将从事学生工作 的辅导员列入思想政治教育者的行列, 讲授思想政治教 育课程的老师基本都是毛概或者马列老师。传统 “仁” 文化思想政治内容如何进思政课堂呢?

首先, 从学校角度来看, 要重视传统文化思想政治 内容教育。学校要清楚的看到传统文化思想政治内容教 育的重要性。这就要求高校充分发挥教师的课堂创新功 能, 寻找传统文化精华部分在思想政治教育课堂进行讲 解, 吸引学生兴趣。一是要丰富思想政治教育内容, 将 传统文化因素加入思想政治教育课程。二是要积极开展 相关传统文化活动, 引起师生高度重视。我国传统文化 体现出来的精神气质, 可以吸引众多的师生参与进来。 如江西科技师范大学文学院先后开展 “楚调唐音歌吟” 专场汇报演出及校级主题楹联大赛, 这对提升大学生传 统文化修养, 让同学们体会到歌吟艺术及祭联等传统文 化, 让同学们能在传统文化氛围中进行思想政治文化意 识的提升有重要的作用。

第二, 从老师的角度出发, 要创新传统文化思想政 治教育方式。在进行传统文化思想政治教育的过程中, 高校老师要注重课堂方式的创新, 一是要寻找新的教育 内容, 设四书五经、诸子百家等经典导读的选修课; 将 中华优秀传统文化纳入思想政治理论课程中, 丰富思想 政治理论课教材内容, 使之更具生动性和可读性; ${ }^{\left[{ }^{[5]}\right.}$ 组织 收看并讨论央视《百家讲坛》开讲的《论语》、《三国》、

《红楼梦》等经典导读; 利用中华民族的春节、清明、 端午、中秋、重阳等传统节日和重要的历史人物、历史 事件的纪念日, 举办主题鲜明、形式多样、重在传统文 化体验的校园第二课堂活动; 二是要课上课下、网上网 下多和学生沟通交流。以垃圾分类为例, 这是对生态环 境的保护，老师可以让学生从传统 “仁” 文化的典籍文 献中找出古人在保护环境方面有什么观点和贡献, 这些 观点有哪些时代特征, 有哪些是一直发展延续的传统优 秀文化。

第三, 从学生的角度出发, 要创造传统文化学习的 良好氛围。良好的学习环境, 能塑造学生良好的人格。 要从学生的角度出发, 创造传统文化学习生活氛围。一 方面我们要注重在学生熟悉的地方贴一些宣传语, 这些 宣传语既是学生熟悉并且能够理解的, 又能够让学生感 到亲切。另一方面, 要充分利用 “学习强国” 等校内外 媒体, 为学生树立道德榜样, 掀起师生重视传统文化的 热潮。

在进行传统 “仁” 文化相关思想政治教育工作时, 
效途径。思想政治教育工作者一定要重视并利用好传统 “仁”文化，以增强自身道德修养，丰富德育内容，充 实思想政治教育理念、改革课程设置，合理利用思想政 治教育课堂及第二课堂, 精心设计课程内容、教育方式, 鼓励大学生积极主动的了解中国传统文化, 对思想政治 教育进行课程改革, 在专业课堂中融入中国传统文化教 育和思想政治教育, 以便适应新时代思想政治教育的需 要，真正促进思想政治教育工作的发展，培养和提高大 学生的德育, 造就大量优秀合格的人才。

\section{2 培养思想政治教育工作者自身传统 “仁” 文化教育意识}

思想政治教育工作者传统 “仁” 文化道德素质的高 低, 直接决定着在学生中进行思想政治教育的质量。思 想政治教育工作者要培养自身传统“仁”文化教育意识, 保证自己的道德水平, 进一步对学生进行人格魅力影 响, 具体内容包括:

一是家国情怀, 注重德教。孔子说: “主忠信, 徒 义, 崇德也。”(《论语・颜波》) 孟子云: “以力服人者, 非心服也, 力不赡也; 以德服人者, 中心悦而诚服也, 如七十子之服孔子也。” (《孟子・公孙丑上》) 这是对传 统 “仁” 文化对德育师资队伍的基本要求。思想政治教 育工作者必须有 “修身、齐家、治国、平天下” 的家国 情怀, 注重自身爱国主义思想道德文化修养, 爱学生, 爱学校, 爱国家。

二是道德修养，坚持身教示范。作为思想政治教育 一线老师, “道高为师, 德高为范”。有一些老师认为教 师是自己谋生的手段, 没有做到从道德上约束和管理自 己, 缺乏对传统 “仁” 文化的科学判断和分析, 不能用 传统 “仁” 文化的理论和思想推进学科研究, 没有在教 学中潜移默化地发挥出教育示范作用, 达到对学生科学 精神和人文精神的交叉渗透。

三是教学方法, 实施因材施教。思想政治教育工作 者应该积极钻研思想政治教育教学方法, 深入掌握、领 会传统 “仁” 文化的深刻内涵, 实施因材施教。前者要 充分运用各种教育手段及技术, 采取大学生容易接受的 方法, 注重参与体验式教学, 激发学生学习传统 “仁” 文化内涵的积极性和主动性, 从而提高思想政治教育的 效率及质量。对于活动在大学生一线思想政治教育工作 的群体, 学校除了要进行传统文化教育培训外, 也要进 行相关的教学技能培训, 建设一支专业技能高、素质强 的思想政治教育队伍。 ${ }^{[6]}$

\section{6. 结束语}

传统 “仁” 文化在大学传统文化传授、培养大学生 德育方面起着举足轻重的作用, 是思想政治教育工作者 进行思想政治教育工作、践行社会主义核心价值观的有

\section{基金项目}

江西省教育厅人文社会科学思想政治工作专项项 目 “新形势下大学生党员教育机制创新研究” 阶段成 果 (SZZX1722)。

\section{REFERENCES}

[1] Zi Meng. (2015) Mencius. Henan people's Publishing House, Zhengzhou.

[2] Xi Zhu. (2011) Notes to chapters and sentences of four books. Zhong Hua Book Company, Beijing.

[3]Yuanyuan Wei,Ruiping Du. (2010) The status quo and value realization of traditional culture in Ideological and political education in Colleges and Universities. Journal of social science of Shanxi University,05: 75-76.

[4]Wenzhi Liu. (2008) On the relationship between Chinese traditional culture and moral education. Theoretical realm,09: 139.

[5]Wannian $\mathrm{Hu}$, Xiaoyun Wu. (2016) The return and integration of excellent traditional culture in the ideological and political education of College Students. College counselor Journal,01: 49.

[6]Qi Li. (2017) On the current situation and development of the combination of Chinese excellent traditional culture and ideological and political education in Colleges and Universities. Cultural and educational materials,21: 69 . 